\title{
Effect of Tualang honey on the anastomotic wound healing in large bowel anastomosis in rats-A randomized controlled trial
}

Muhammad Izani Aznan ${ }^{1 \dagger}$, Omaid Hayat Khan², Allah Obhayo Unar ${ }^{1 \dagger}$, Sharifah Emilia Tuan Sharif ${ }^{3}$, Amer Hayat Khan ${ }^{2}$, Syed Hassan Syed Abd. Aziz and Andee Dzulkarnaen Zakaria ${ }^{1 *+}$

\begin{abstract}
Background: Honey has long been used for the treatment of number of ailments and diseases including surgical wounds. Current study evaluates the effectiveness of Tualang honey (TH) for large bowel anastomotic healing in Wistar rats.

Methods: Thirty male Wistar rats were given a 3 centimeter infra-umbilical laparotomy wound, in 'flicted on their abdomen. The colonic transection was performed at $5 \mathrm{~cm}$ distal to caecum, with end to end anastomosis of colon segment. They were divided into two groups. Group I was fed with standard rat chow and water. Meanwhile, Group II apart from standard feed, was also given TH $1.0 \mathrm{~g} / \mathrm{kg}$ every morning until day seven post operatively. Afterwards, anastomotic bursting pressures were measured and histopathological examination on the anastomosis line was performed with light microscopes. The data from two groups were analyzed by Independent paired t test for continuous variables.

Results: It was found that the tensile strength of colon anastomosis ( $95 \% \mathrm{Cl} ; p=<0.001)$ and the histopathological study including fibroblast count $(p=<0.001)$ and inflammatory cells $(p=0.002)$ showed statistically significant difference in the favor of TH-treated group. Meanwhile, neovascularization formation was not statistically significant ( $p=0.807)$; however, the overall count in the TH group was high.

Conclusion: Oral treatment with $\mathrm{TH}$ enhances anastomotic wound healing by increasing the number of fibroblasts and by decreasing inflammatory cells leading towards increased wound strength.
\end{abstract}

Keywords: Anastomosis, Anastomotic bursting pressures, Honey, Wound healing

\section{Background}

Since the very beginning of 17th century, intestinal anastomosis procedure is being practiced and has been considered a promising surgical intervention for patients with diseased bowels. However, a disastrous complication of intestinal anastomosis is anastomotic leak resulting in peritonitis, which is associated with high mortality, morbidity and increased hospital stay [1].

\footnotetext{
* Correspondence: andee778@gmail.com

${ }^{\dagger}$ Equal contributors

'Department of Surgery, School of Medical Sciences, Universiti Sains

Malaysia, Health Campus, Kota Bharu 16150, Malaysia

Full list of author information is available at the end of the article
}

Apart from modern surgical techniques and precautions, intra-abdominal adhesion formation after surgery is still an obvious manifestation [2]. Adhesion formation has similar pathways as that of wound healing thus modulation of the release factors could be expected to affect its formation $[3,4]$. The incidence of anastomotic leak varies widely with a usual range between $2.7 \%$ to $26 \%$ in abdominal surgeries $[1,5]$, risk factors for which normally remain type of procedure, patient demographics and surgical techniques. $[6,7]$ A study by Neil Hyman et al. showed that leakage of intestinal anastomosis was diagnosed clinically ranging from day one to nineteenth day post operatively [5]. Mortality rates associated with 
anastomotic leak after surgery range from $6.2 \%$ to $37 \%$ $[8,9]$. The onset of anastomotic leakage increases the risk of mortality four to seven-folds [10,11].

Various methods including perioperative management, careful operative techniques, post-operative care and use of different healing agents such as honey, Aloe Vera, snakehead fish (Haruan) are being practiced in order to decrease the incidence of the leak and/or to facilitate the anastomotic healing process, thus improving patient outcome [12-15]. Honey has a long history of traditional use for wound healing and has been referred extensively in the medical literature since ancient times. Emre A et al. in 2010 showed that honey improved anastomotic wound healing in rats [16]. In many different animal studies, honey indeed has been proven effective, as in studies by Subrahmanyam in 1996 showed that wound dressing with honey healed faster [17].

The aim of the present study is to investigate the effect of $\mathrm{TH}$ in large bowel anastomosis in rats, undertaking its effect on tensile strength of large bowel anastomosis by measuring the bursting pressure and its effect on histopathology examination.

\section{Methods}

A Randomized Control Trial study was conducted over a period of eight months at the Animal Research and Service Centre (ARASC) of Universiti Sains Malaysia, Kubang Kerian. Tualang honey was supplied by the Federal Agriculture Marketing Authority (FAMA) office in Kedah, Malaysia. Study was approved by the Animal Ethical Committee and the sample size of 30 rats was obtained using certified software (PS Software). By using block randomization, all rats $(N=30)$ were categorized into two groups $(t=2)$; one control group and the other as study group which was administered Tualang honey (TH) orally. So rats were divided into 15 nomogenous groups with 2 rats in each group. One of the rats in individual nomogenous group was randomly assigned as a control and the other one as the study. Colonic resection and end to end bowel anastomosis was performed on all the thirty rats.

\section{Materials}

\section{Tualang Honey}

In Malaysia, there are varieties of honey available depending on the type of bees and where they make their combs. The most famous of which is $\mathrm{TH}$, which gets its name from the rock bees (Apis dorsata) [18] that make their hives high up on the branch of Tualang tree (Kompassia excelsa) located in the north west region of Peninsular Malaysia [19]. It has been used traditionally in the local community for the various purposes including treatment for many diseases, as a food, supplement and also as a preservative. The $\mathrm{TH}$ is expensive compared to other honey as it is the best among local honey due to its outstanding therapeutic, antiinflammatory, anti-oxidant, immunity enhancing, antitumor, anti-diabetic and anti-bacterial qualities including its activity against number of gram positive as well as gram negative species including Klebsiella pneumonia,Pseudomonas spp.and Acinetobacter baumannii [20]. Apart from its effect on wound management, $\mathrm{TH}$ also provides an additional antioxidant effect to many organs for example pancreas especially in diabetic rat model. This protective effect on pancreas against oxidative stress might also partially contribute to the hypoglycemic effect of $\mathrm{TH}$ in diabetic model [14].

\section{Animals}

Thirty male Wistar rats at the age of 90 days, weighing about 250 - 400gm were classified for the study. All thirty male rats were kept in ARASC one week prior to study and were fed with free access to standard commercial diet and water ad libitum throughout the study and were kept in separate cages under constant temperature of 21 to $22^{\circ} \mathrm{C}$ to maintain healthy and clean environment. No mechanical bowel preparation was done prior to the experimental procedure and neither any intraoperative bowel irrigation was performed.

Surgical Procedure: The procedure was conducted in several sessions for all the thirty rats in both groups. The rats were anesthetized with an intramuscular Ketamine (Troy Lab. Pty Ltd, Australia) $60 \mathrm{mg} / \mathrm{kg}$ of the body weight. This anesthesia was given by a specialized team from the department of veterinary medicine of Universiti Sains Malaysia. The abdomen was shaved during anesthesia and the rats were placed and secured in dorsum recumbence position. When fully anaesthetized, the shaved area was cleaned and the operation site was isolated with sterile towel. Afterwards the surgical procedure was performed under aseptic conditions.

A $3 \mathrm{~cm}$ incision initiating from the infra umbilicus, at the midline, along the line of linea alba was made. Abdomen was opened in layers until the peritoneum was exposed and then the caecum was identified. Large bowel was transected at $5 \mathrm{~cm}$ distal to caecum. End to end anastomosis of transected colon was performed using 6/0 Premilene (B Braun Aesculap, Germany) in single layer interrupted fashion. This suture was selected as it is commonly used and is monofilament (less tissue damage). The abdominal muscle layer was closed as continuous sutures with 4/0 Premilene ${ }^{\circ}$ (B Braun Aesculap, Germany) and the same type of sutures were used to close the skin and subcutaneous tissue layer. Postoperative dressing, in the form of abdominal bandage, was applied to prevent self-mutilation. Right after the procedure, they were monitored for spontaneous 
breathing effort and movement and their daily activity and feeding habits were also observed.

After the surgical procedure was completed on all the thirty rats, they were kept in an individual cage according to their group and number. Fifteen rats in control group (Group I) were fed with standard rat chow and water, while other fifteen rats in the study group (Group II) were given Tualang honey (TH) apart from standard rat chow and water. Tualang honey $(1.0 \mathrm{~g} / \mathrm{kg})$ was given orally (once daily, every morning) until the seventh day post-operatively. On the seventh day after the procedure, all the rats were sacrificed. The rats were euthanized using carbon monoxide gas until death. An incision was made on the same anterior abdominal wall wound and the anastomotic site was exposed outside the abdominal cavity. Large bowel was resected $2.5 \mathrm{~cm}$ proximally and distal to the anastomotic site from all the animals and were tested for biomechanics and histology accordingly.

Tensile strength measurement: In both groups, $5 \mathrm{~cm}$ segment was excised proximally and distal to the anastomotic site, positioning it in the center. Feces that were contained inside the colon segment were gently removed. The suture at the anastomotic site was not removed. One end of the excised segment was tied and the other end was catheterized with polyurethane tube (Fore Sight Industries, Sdn Bhd, Malaysia) and staysuture was tied circumferentially incorporating both tissue and the tube so as to prevent air leakage. The external end of the tube, a syringe (Terumo Corp. Tokyo Japan) with infusion pump (Teruma Corp. Tokyo, Japan) and a mercury sphygmomanometer (Accoson Ltd, United Kingdom) were all connected to each other by 3 way of T-shaped adapter. The colon segment was then placed in a container filled with saline and room air was pumped into tube at a rate $5 \mathrm{ml} / \mathrm{min}$ using infusion pump. The manometer reading at the instant of sudden pressure decrease or when bubbles were seen was recorded as the bursting pressure. The maximum pressure reading before the pressure declined suddenly was recorded as the bursting pressure [21]. The suture at the anastomotic site was not removed during this process. The equipment used for bursting pressure measurement was setup using local material because anastomotic sample was small in size.

Histopathology examination: The tissue specimens $(5 \mathrm{~cm}$ colonic segment with the anastomosis site in the center in $10 \%$ formaline) were sent to the histopathological laboratory on the same day of procedure. The specimens were processed for slide examination. The slides obtained were examined under the light microscope (Olympus CX 31 ) over a high power field (40x) by a single pathologist who was assigned to help in specimen analysis. Examination was done over ten fields per specimen in a random fashion and an average was taken as the final count. Hematoxylin and Eosin stains (H\&E stain) were used and the cells were seen in all layers of the colon and they included fibroblast count, inflammatory cells (abundant lymphoplasma cells, macrophages and polymorphonuclear leucocytes) and blood vessels which were counted semi quantitatively and graded histologically in a blind fashion, using the $0-4$ Ehrlich and Hunt numerical scale (Table 1) [22].

Statistical Analysis: All data were expressed as mean \pm Standard Deviation (SD) and tabulated in the form of table (Table 2). The Statistical Package for the Social Science (SPSS) version 18.0 for windows was used in statistical analysis. The data from two groups were analyzed by Independent paired $t$ test for continuous variables. Difference was considered statistically significant when $P<0.05$.

\section{Results}

The results for the tensile strength by bursting pressure measurement between Group I (control) and Group II (study) are shown in Fig. 1. On the seventh day postoperatively, mean bursting pressure for Group II was significantly higher which was $241.33 \mathrm{mmHg}$ (SD of 17.27) compared to Group I $187.33 \mathrm{mmHg}$ (SD 16.24) with mean difference of -54.00 (CI $95 \%-66.54,-41.46$ ) $(p<0.001)$. There was a significantly higher fibroblast count in Group II with mean of 2.87 cells $/ \mathrm{mm}^{2}$ (SD 0.35 ) compared to Group I with the mean of 1.93 cells/ $\mathrm{mm}^{2}$ (SD 0.4) on the seventh day postoperatively. The difference between fibroblast count in both the groups was statistically significant $(p<0.001,95 \%$ CI $-1.24,-$ $0.63)$. Subjects treated with $\mathrm{TH}$ in the study group had statistically significant lower mean inflammatory cells count compared to those in control group with mean difference of -0.60 (95\% CI $-0.60,-0.24, p=0.002)$. There was no significant difference in neovascularization between both the groups. (95\% CI $-0.62,0.49, p=0.807$ ).

\section{Discussion}

Honey is a supersaturated sugar solution, some of the components of which are added by the bees while the rest depend upon the plant origin from which the nectar

\begin{tabular}{ll} 
Table $\mathbf{1}$ Histological grading scale [22] & \\
\hline Grade & Histologic analysis \\
\hline 0 & No evidence \\
$1+$ & Occasional evidence \\
$2+$ & Light scattering \\
$3+$ & Abundant evidence \\
$4+$ & Confluence cells or fibres \\
\hline
\end{tabular}


Table 2 Results of manometric studies among the two studied groups

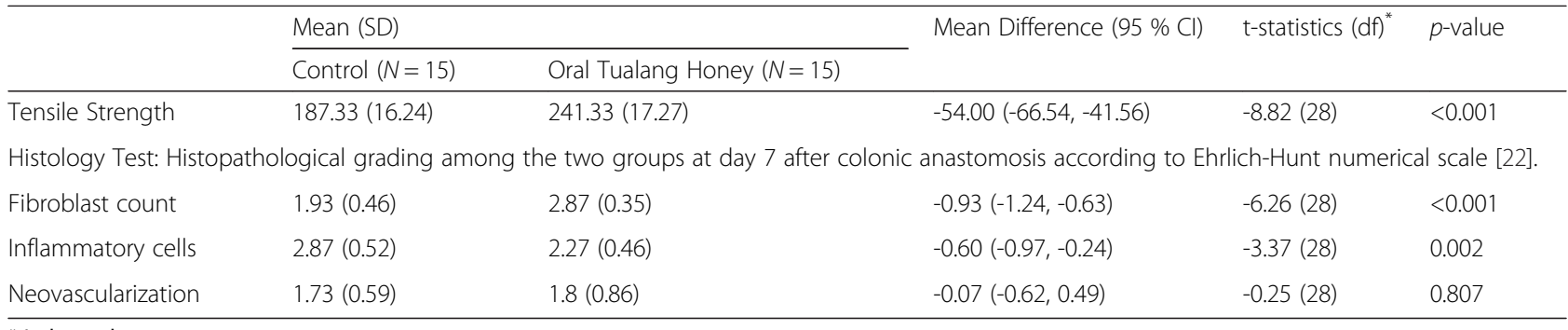

* Independent t test

has been collected, geographical location and the season. Acidity, hydrogen peroxide content, osmotic effect, nutritional and antioxidants content, stimulation of immunity, and unidentified compounds of honey are the factors responsible for its antibacterial activity; furthermore, by decreasing prostaglandin levels, elevating nitric oxide levels and exerting prebiotic effects the inflammatory and healing processes are also promoted [23]. However, no definite mechanism has been identified so far to explain the anti-inflammatory action of honey, which suggests that honey may have a number of effects on the molecular mechanisms of wound healing [15].

Anastomotic leakage, even under best circumstances, in colorectal surgery is approximately $3 \%$ [24]. The efficiency of the topical application of honey on wounds or burns has been reported already in number of studies, however some of them exhibited that systemic administration of honey mainly intraperitoneal yields better results than topical treatment [25]. Current study focused on the oral administration of honey and used the bursting strength apart from histopathology examination to measure the healing of colonic anastomosis which is in accordance with study conducted by Nelson and Anders et al. [26] who advocated the use of bursting wall tension as a measure of bursting strength, considering it more accurate measurement. This finding was similar with study done by Gollu A. et al. in 2008 where they found that the colonic bursting pressures of the honey group (average:188.68 \pm 14.26) were significantly better than the control group (average:149.72 $\pm 15.48, p=0.001$ ) [27]. Most studies evaluated that the maximum strength gained was seen between fourth to seventh day postoperatively. Jiborn $\mathrm{H}$ et al. (1978) found that on the seventh postoperative day, bursting strength values in the two study groups reached almost the same range as that of un-operated controls [28]. This finding implies that the anastomosis, in fact, is as strong as the surrounding wall and can be accomplished as early as the seventh postoperative day. In the

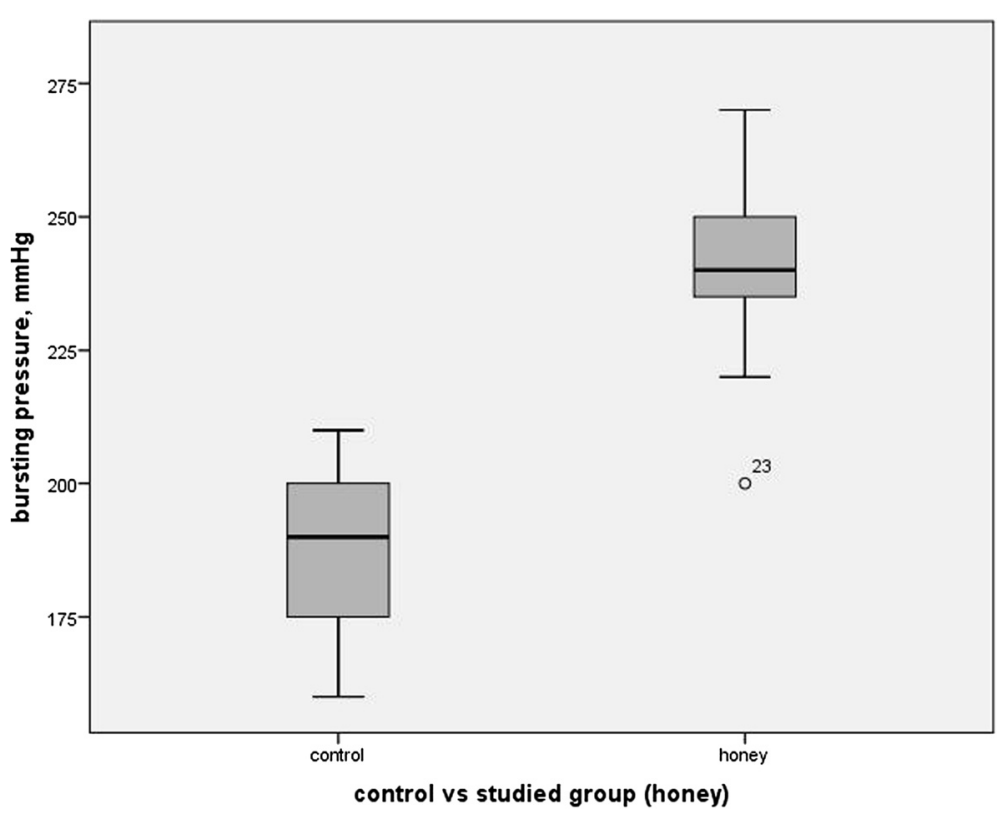

Fig. 1 Comparison of bursting pressure (tensile strength) between groups treated with $\mathrm{TH}$ and control group 
current study, right side of colon was chosen because of the presence of cecum as a reference point for determining the site of bowel transection and anastomosis.

On the other hand, the recovery of tensile strength of healing skin is related to several factors including healing time and nutritional status of the healing tissues [29]. The increase in tensile strength of honey treated wounds could reflect not only the increased collagen content but also acceleration of collagen maturation resulting from the cross-linking of the collagen deposited by the fibroblasts. A slow increase in wound tensile strength corresponds to increase in fibroblasts, which begin to produce immature collagen during the proliferative phase of wound healing [30]. Because, fibroblasts play an important role in producing the collagen necessary to restore the tensile strength of wounded skin [31], the increased tensile strength in honey treated wound might be due to the increase in collagen concentration per unit area and stabilization of the fibrils [32]. Maturation of collagen fibrils resulted in stable cross links between several chains and these cross link are responsible for the gain in strength. In addition, honey was claimed to have high levels of glycine, methionine, arginine and proline which play definite roles in collagen formation and deposition [33]. Current study found that there was a significant higher fibroblasts count in TH group compared to the control groups on the day seven post treatment as seen in Fig. 2 and Fig. 3 which is in concordance with other studies which explained the similar phenomenon like in one study, in the propolis group, the proliferation, activation, and synthesis capacity of fibroblasts were much better than the control group and in another one, immature fibroblast were present on the first day post operatively in honey group and these cells matured and acquired the characteristic ultrastructural features of actively synthetic fibroblasts on the third day $[34,35]$.

Beside sugars, amino acids, minerals, vitamins and low level of hydrogen peroxide, honey, on the other hand, also contains some important components required to enhance synthesis of glycosaminoglycans which are one of the major components produced by fibroblasts in the wound area $[15,33]$. Furthermore, TH possesses better antioxidant effects against a variety of reactive oxygen species when compared to other local Malaysian honeys like Gelam, Indian forest, and pineapple honeys [36].

Apparently in the current study, TH successfully showed statistically significant effect in lowering mean inflammatory cells count compared to those in control, however, it failed to statistically signify the slightly higher neovascularisation in those treated with $\mathrm{TH}$ compared to the control but it can be referred clinically significant as angiogenesis (which was actually high in TH group) eventually enhances wound healing process. This study failed to produce significant neovascularization as compared to another study conducted by Kilicoglu et al. [34], which may be attributed towards bigger sample size in that study compared to the current study. The dose of honey administered may be another factor involved regarding angiogenesis, as evident by multiple pilot studies, the best result on wound healing could be obtained at the dose of $1.5-2.0 \mathrm{ml}$ orally plus $0.1-0.15 \mathrm{ml} / \mathrm{cm}^{2}$ topically or by topical application of $0.2-2.5 \mathrm{ml} / \mathrm{cm}^{2}$ [37]. However, overdosage caused an overgrowth and dehydration of the granulation tissue whereas lower doses resulted in less or no response; current study used $1.0 \mathrm{~g} / \mathrm{kg}$ of Oral $\mathrm{TH}$ per day for 7 days postoperatively, which may also explain less angiogenesis as compared to other studies.

\section{Limitations}

A little than usual dosage of $\mathrm{TH}$ was used so as to prevent overgrowth of the granulation tissue and also because further studies are still needed to come up with the optimum dose regimen regarding enteral feeding. There were some limitations of our study regarding cost which included the failure to assess collagen matrix production in the histopathology examination, only cell proliferation phase on day seven was assessed and also failure to attempt other types of biomechanical testing (e.g. elastic modulus).

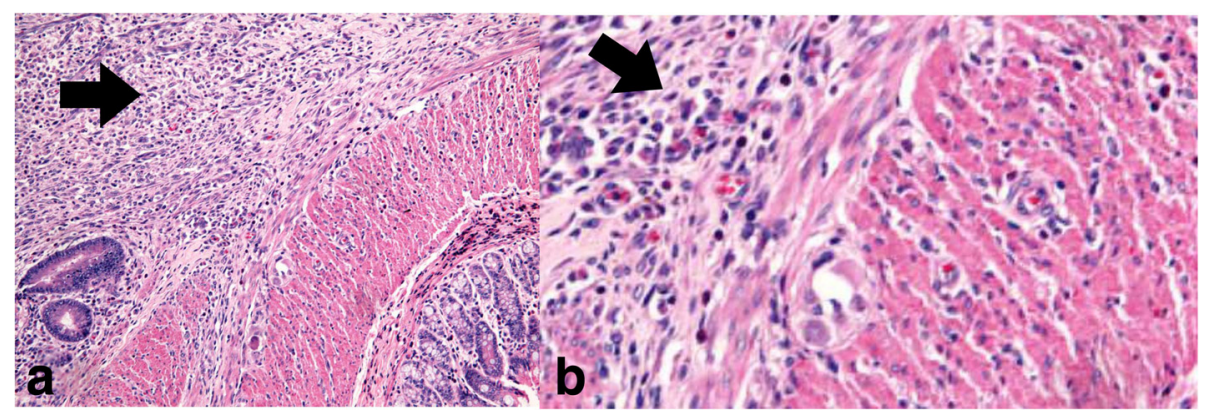

Fig. 2 Lack of fibroblast count and abundance of inflammatory cells infiltration in control group [black arrows], H\&E stain, X20(a), digitally zoomed $2 \times(b)$ (Courtesy of Pathology Department, HUSM) 


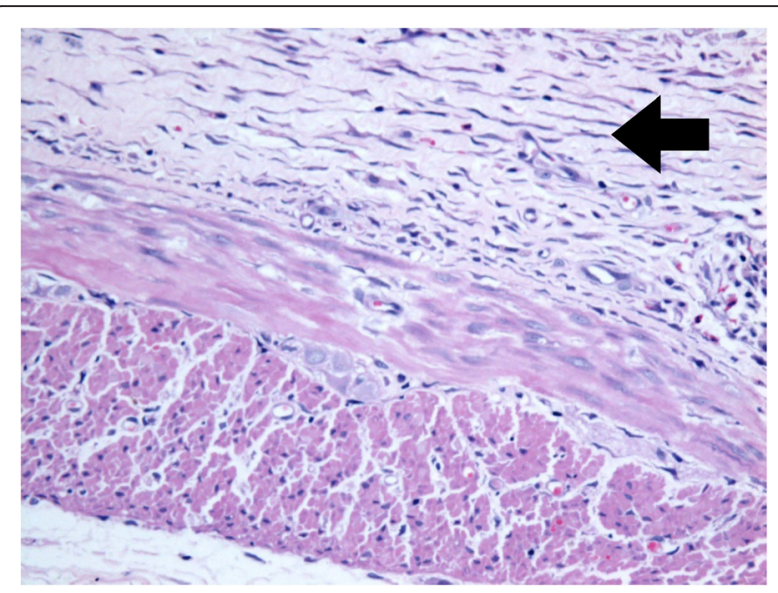

Fig. 3 An increased fibroblast [black arrow] and less inflammatory cells infiltration in the TH group, H\&E stain, X40 (Courtesy of Pathology Department, HUSM)

\section{Further Research}

Since the aim of this study was to evaluate the effects of $\mathrm{TH}$ in the enhancement of anastomotic healing, and not the mechanism of this effect, only possible mechanisms that might be responsible for positive effects of honey was hypothesized. Further studies are needed for the evaluation of the exact mechanism of healing. The bioavailability of honey should also be studied to evaluate the best dose for a better wound healing through enteral feeding and study regarding pre-operative administration of $\mathrm{TH}$ may also lead to a better understanding of the optimum treatment regimen. This experimental study included normal test subjects, further studies may look at malnourished or subjects with fecal contamination or peritonitis to evaluate the extent of effectiveness of TH in promoting wound healing. Results from the studies investigating the mechanism of action and controlled clinical trials, TH may be used for the prevention of anastomotic failure after major operations.

\section{Conclusion}

Malaysian TH enhances not only the early phase of colon anastomotic healing by inhibiting the inflammatory response, but also stimulates the collagen synthesis of fibroblasts. The exact mechanisms of improved anastomotic wound healing by honey administration are not known, although increase of neoangiogenesis, mononuclear cell infiltration, and the stimulation of collagen synthesis are all involved.

\section{Competing interests}

The authors declare that they have no competing interests.

\section{Authors' contributions}

MIA, AOU and ADZ allocated research materials, carried out the surgeries and participated in the animal control and handling. OHK drafted the manuscript. SH, AHK \& OHK carried out the bursting pressure measurements. SETS helped in pathology studies and participated in the design of the study and performed the statistical analysis. ADZ conceived of the study, and participated in its design and coordination and helped to draft the manuscript. All authors read and approved the final manuscript.

\section{Acknowledgment}

The authors would like to acknowledge the support of staff and adminstration of Universiti Sains Malaysia (USM) for providing with the research materials, grant (number: 304/PPSP/61312068), animal research \& pathology services and publication processing of the current study and would also like to thank Federal Agricultural and Marketing Authority (FAMA) office for the provision of TH.

\section{Author details}

${ }^{1}$ Department of Surgery, School of Medical Sciences, Universiti Sains Malaysia, Health Campus, Kota Bharu 16150, Malaysia. ${ }^{2}$ Discipline of Clinical Pharmacy, School of Pharmaceutical Sciences, Universiti Sains Malaysia, Penang 11800, Malaysia. ${ }^{3}$ Department of Histopathology, School of Medical Sciences, Universiti Sains Malaysia, Health Campus, Kota Bharu 16150, Malaysia.

Received: 19 April 2015 Accepted: 19 January 2016

Published online: 23 January 2016

\section{References}

1. Bruce J, Krukowski ZH, Al-Khairy G, Russell EM, Park KGM. Systematic review of the definition and measurement of anastomotic leak after gastrointestinal surgery. Br J Surg. 2001;88(9):1157-68.

2. Ellis $\mathrm{H}$. Medicolegal consequences of postoperative intra-abdominal adhesions. J R Soc Med. 2001;94(7):331-2.

3. Baykal A, Ozdemir A, Renda N, Korkmaz A, Sayek I. The effect of octreotide on postoperative adhesion formation. Canadian journal of surgery Journal canadien de chirurgie. 2000;43(1):43-7.

4. Cahill RA, Redmond HP. Cytokine orchestration in post-operative peritoneal adhesion formation. World journal of gastroenterology: WJG. 2008;14(31):4861-6.

5. Hyman N, Manchester TL, Osler T, Burns B, Cataldo PA. Anastomotic leaks after intestinal anastomosis: it's later than you think. Ann Surg. 2007;245(2):254-8.

6. Chang J, Ferguson H, Gates Z: Risk Factors for Anastomotic leaks. Medical Posters 2014;1(5).

7. Suding $P$, Jensen $E$, Abramson MA, Itani K, Wilson SE. Definitive risk factors for anastomotic leaks in elective open colorectal resection. Archives of surgery (Chicago, III : 1960). 2008;143(9):907-11. discussion 911-902.

8. Vignali A, Fazio WW, Lavery IC, Milsom JW, Church JM, Hull TL, et al. Factors associated with the occurrence of leaks in stapled rectal anastomoses: a review of 1,014 patients. J Am Coll Surg. 1997;185(2):105-13.

9. Golub R, Golub RW, Cantu Jr R, Stein HD. A multivariate analysis of factors contributing to leakage of intestinal anastomoses. J Am Coll Surg. 1997;184(4):364-72.

10. Alves A, Panis Y, Trancart D, Regimbeau J-M, Pocard M, Valleur P. Factors associated with clinically significant anastomotic leakage after large bowel resection: multivariate analysis of 707 patients. World J Surg. 2002;26(4):499-502.

11. McArdle C, McMillan D, Hole D. Impact of anastomotic leakage on long-term survival of patients undergoing curative resection for colorectal cancer. Br J Surg. 2005;92(9):1150-4.

12. Inan A, Şen M, Koca C, Ergin M, Dener C. Effects of Aloe vera on colonic anastomoses of rats. Surg Pract. 2007;11(2):60-5.

13. Mustafa A, Sujuti H, Permatasari N, Widodo MA. Determination of nutrient contents and amino acid composition of Pasuruan Channa striata extract. IJSTE. 2013;2(4):1-11.

14. Jais AM, Matori MF, Kittakoop P, Sowanborirux K. Fatty acid compositions in mucus and roe of Haruan, Channa striatus, for wound healing. Gen Pharmacol. 1998:30(4):561-3.

15. Lusby PE, Coombes A, Wilkinson JM. Honey: a potent agent for wound healing? J Wound Ostomy Continence Nurs. 2002;29(6):295-300. 
16. Emre A, Akin M, Isikgonul I, Yuksel O, Anadol AZ, Cifter C. Comparison of intraperitoneal honey and sodium hyaluronate-carboxymethylcellulose (SeprafilmTM) for the prevention of postoperative intra-abdominal adhesions. Clinics. 2009;64(4):363-8.

17. Subrahmanyam M. Honey dressing versus boiled potato peel in the treatment of burns: a prospective randomized study. Burns. 1996;22(6):491-3.

18. Mohamed M, Sirajudeen K, Swamy M, Yaacob NS, Sulaiman SA. Studies on the antioxidant properties of Tualang honey of Malaysia. Afr J Tradit Complement Altern Med. 2010;7(1):59-63.

19. Ahmed S, Othman NH. Review of the medicinal effects of tualang honey and a comparison with manuka honey. Malays J Med Sci. 2013:20(3):6-13.

20. Nasir NA, Halim AS, Singh KK, Dorai AA, Haneef MN. Antibacterial properties of tualang honey and its effect in burn wound management: a comparative study. BMC Complement Altern Med. 2010;10:31.

21. Aslan A, Temiz M, Hakverdi S, Polat G, Tumer C, Temiz A, et al. Effect of mesalamine on healing in experimental colon anastomosis: a randomised experimental study. Int J Surg. 2008;6:40-4.

22. Ehrlich HP, Tarver H, Hunt TK. Effects of vitamin A and glucocorticoids upon inflammation and collagen synthesis. Ann Surg. 1973;177(2):222-7.

23. Al-Waili NS, Salom K, Butler G, Al Ghamdi AA. Honey and microbial infections: a review supporting the use of honey for microbial control. J Med Food. 2011;14(10):1079-96.

24. Buchs NC, Gervaz P, Secic M, Bucher P, Mugnier-Konrad B, Morel P. Incidence, consequences, and risk factors for anastomotic dehiscence after colorectal surgery: a prospective monocentric study. Int J Colorectal Dis. 2008;23(3):265-70.

25. SUGUNA L, CHANDRAKASAN G, RAMAMOORTHY U, JOSEPH KT. Influence of honey on biochemical and biophysical parameters of wounds in rats. J Clin Biochem Nutr. 1993;14(2):91-9.

26. Nelsen TS, Anders CJ. Dynamic aspects of small intestinal rupture with special consideration of anastomotic strength. Archives of surgery (Chicago, III : 1960). 1966;93(2):309-14.

27. Gollu A, Kismet K, Kilicoglu B, Erel S, Gonultas MA, Sunay AE, et al. Effect of honey on intestinal morphology, intraabdominal adhesions and anastomotic healing. Phytotherapy research : PTR. 2008;22(9):1243-7.

28. Jiborn H, Ahonen J, Zederfeldt B. Healing of experimental colonic anastomoses. I. Bursting strength of the colon after left colon resection and anastomosis. Am J Surg. 1978;136(5):587-94.

29. Lu WW, Ip WY, Jing WM, Holmes AD, Chow SP. Biomechanical properties of thin skin flap after basic fibroblast growth factor (bFGF) administration. Br J Plast Surg. 2000;53(3):225-9.

30. Jimenez PA, Rampy MA. Keratinocyte growth factor-2 accelerates wound healing in incisional wounds. J Surg Res. 1999;81(2):238-42.

31. Jorgensen $\mathrm{PH}$, Andreassen $\Pi$. Influence of biosynthetic human growth hormone on biomechanical properties of rat skin incisional wounds. Acta Chir Scand. 1988;154(11-12):623-6.

32. SUGUNA L, CHANDRAKASAN G, Thomas Joseph $\mathrm{K}$. Influence of honey on collagen metabolism during wound healing in rats. J Clin Biochem Nutr. 1992;13(1):7-12

33. Gupta S, Singh H, Varshney A, Prakash P. Therapeutic efficacy of honey in infected wounds in buffaloes. Indian Journal of Animal Sciences. 1992;62(6):521-3.

34. Kilicoglu SS, Kilicoglu B, Erdemli E. Ultrastructural view of colon anastomosis under propolis effect by transmission electron microscopy. World journal of gastroenterology : WJG. 2008;14(30):4763-70.

35. Fedakar-Senyucel M, Bingol-Kologlu M, Vargun R, Akbay C, Sarac FN, Renda $\mathrm{N}$, et al. The effects of local and sustained release of fibroblast growth factor on wound healing in esophageal anastomoses. J Pediatr Surg. 2008;43(2):290-5.

36. Kishore RK, Halim AS, Syazana MS, Sirajudeen KN. Tualang honey has higher phenolic content and greater radical scavenging activity compared with other honey sources. Nutr Res. 2011;31(4):322-5.

37. Aljady A, Kamaruddin M, Jamal A, Mohd Yassim M. Biochemical study on the efficacy of Malaysian honey on inflicted wounds: an animal model. Medical Journal of Islamic Academy of Sciences. 2000;13(3):125-32.

\section{Submit your next manuscript to BioMed Central and we will help you at every step:}

- We accept pre-submission inquiries

- Our selector tool helps you to find the most relevant journal

- We provide round the clock customer support

- Convenient online submission

- Thorough peer review

- Inclusion in PubMed and all major indexing services

- Maximum visibility for your research

Submit your manuscript at www.biomedcentral.com/submit

) Biomed Central 